\title{
MOCVD of GaN Films on Si Substrates Using a New Single Precursor
}

\author{
Seonmi Song, Sun Sook Lee, Seung Ho Yu, Taek-Mo Chung, Chang Gyoun Kim, Soon-Bo Lee, ${ }^{\dagger}$ and Yunsoo Kim \\ Thin Film Materials Laboratorv, Adwanced Materials Division, Korea Research Institute \\ of Chemical Techlologv, Daejeon $305-600$, Korea \\ Department of Chemistrv. School of Molecular Science-BK21, Center for Nanotubes \\ and Nanostructured Composites, Sungkwankw an Cniversit, Suwon 4+0-746. Korea \\ Received February 24.2003
}

\begin{abstract}
Hexagonal $\mathrm{GaN}$ ( $h$-GaN) films have been grown on $\mathrm{Si}(111)$ substrates by metal organic chemical vapor deposition using the azidodiethyylgallium methylamine adduct. $\mathrm{Et}_{2} \mathrm{Ga}\left(\mathrm{N}_{3}\right) \cdot \mathrm{NH}_{2} \mathrm{Me}$. as a new single precursor. Deposition was carried out in the substrate temperature range $385-650^{\circ} \mathrm{C}$. The $\mathrm{GaN}$ films obtained were stoichiometric and did not contain any' appreciable amounts of carbon impurities. It was also found that the $\mathrm{GaN}$ films deposited on $\mathrm{Si}(\mathrm{III})$ had the [0001] preferred orientation. The photoluminescence spectnum of a $\mathrm{GaN}$ film showed a band edge emission peak characteristic of $h-\mathrm{GaN}$ at $378 \mathrm{~nm}$.
\end{abstract}

Key Words : Azidodiethylgallium methylamine adduct. Hexagonal gallium nitride, Metal organic chemical vapor deposition. Single precursor

\section{Introduction}

$\mathrm{GaN}$ has been considered a promising material for optoeletronic devices such as blue and/or UV light emitting diodes (LEDs) and laser diodes (LDs) since it has a direct band gap larger than $3.2 \mathrm{eV}$ at room temperature. ${ }^{\mathrm{T}}$ The growth of GaN films has been conducted primarily by metal organic chemical vapor deposition (MOCVD), using trimethylgallium or triethy'lgallium and a large excess of anmonina. This method requires a high substrate temperature for the decomposition of ammonia. Up until now. one of the main problems in the GaN film growth has been the absence of a suitable substrate material. It has not been possible to grow $\mathrm{GaN}$ as bulk crystal due to the extremely high equilibrium pressure of nitrogen at the growth temperature. ${ }^{j}$ The $\mathrm{Si}$ substrate has a large lattice mismatch with GaN and a large mismatch in thermal expansion coefficients. ${ }^{4}$ nevertheless. it has been used by many research groups ${ }^{5-8}$ Silicon has a variety of advantages such as low cost. large scale availability with high quality: and good thermal and electrical conductivities. It is also very important that the optoelectronic material $\mathrm{GaN}$ be deposited on the universal substrate Si. for their sy'nergistic combination for future device fabrication.

To lower the deposition temperature of $\mathrm{GaN}$. many attempts have been made such as activation of nitrogen sources by plasma and use of alternative precursors. It is also desirable to be able to avoid the highly pyrophoric source materials such as trimethylgallium or triethylgallium. The growth of $\mathrm{GaN}$ films has been attempted to solve these difficulties using the single molecular precursors.

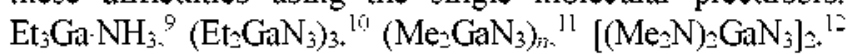
$\left[\mathrm{Me}_{2} \mathrm{GaNH}\left(\mathrm{NMe}_{2}\right)_{2}\right]^{13}\left(\mathrm{H}_{2} \mathrm{GaN}_{3}\right)_{3}{ }^{14.15}\left(\mathrm{Et}_{2} \mathrm{GaNlH}_{2}\right)_{3}{ }^{16}$ $\left(\mathrm{Me}_{2} \mathrm{GaNH}_{2}\right)_{3}$ and $\left(\mathrm{Et}_{2} \mathrm{GaNH}^{7} \mathrm{Bu}\right)_{2}{ }^{17}\left(\mathrm{~N}_{3}\right)_{2} \mathrm{Ga}\left[\left(\mathrm{CH}_{2}\right)_{3} \mathrm{NMe}_{2}\right] .{ }^{18}$ $\mathrm{Et}_{2} \mathrm{Ga}\left(\mathrm{N}_{3}\right) \cdot \mathrm{H}_{2} \mathrm{NNH}_{2} \cdot{ }^{1.9}$ and $\mathrm{Et}_{2} \mathrm{Ga}\left(\mathrm{N}_{3}\right) \cdot \mathrm{MeHNNH}{ }_{2}{ }^{210}$ for low

\footnotetext{
"Corresponding author: E-mail: yunsukim akrict.re.kr
}

deposition temperatures and correct stoichiometry of the resulting films with varying degrees of success. Single source precursors. with ready-made gallium and nitrogen bonds. have been used for the growth of $\mathrm{GaN}$ films at low temperatures. The advantages of the single precursor method are low growth temperature. absence of toxic gases. and easy process control. 21

In an attempt to find a more suitable precursor for the deposition of $\mathrm{GaN}$. we decided to use a new single molecular precursor azidodiethylgallium methylamine adduct. $\mathrm{Et} \mathrm{t}_{2} \mathrm{Ga}\left(\mathrm{N}_{3}\right)$. $\mathrm{NH}_{2} \mathrm{Me}$. Azidodiethỵlgallium (diethylgallium azide) has been used for the deposition of $\mathrm{GaN}$ as mentioned above. but it exists as a trimer. with a high formula weight. and therefore does not have high volatility as an MOCVD precursor. However. by coordinating the central gallium atom with a neutral electron-donor ligand. a monomeric species that has higher volatility can be made. The adduct precursor $\mathrm{Et}_{2} \mathrm{Ga}_{(}\left(\mathrm{N}_{3}\right)$. $\mathrm{NH}_{2} \mathrm{Me}$ is one of a series of compounds we have synthesized to this end. In this study the deposition of GaN thin films was performed on $\mathrm{Si}(111)$ substrates by MOCVD in the temperature range $385-650^{\circ} \mathrm{C}$ using the precursor. The $\mathrm{GaN}$ films deposited were characterized by X-ray photoelectron spectroscopy (XPS). X-ray diffraction (XRD). scanuing electron microscopy (SEM), and photoluminescence (PL).

\section{Experimental Section}

Synthesis of azidodiethylgallium methylamine adduct $\left[\mathrm{Et}_{2} \mathrm{Ga}\left(\mathrm{N}_{3}\right) \cdot \mathrm{NH}_{2} \mathrm{Me}\right.$. To a solution of $\mathrm{GaCl}_{3}(1.50 \mathrm{~g} .8 .50$ mumol) in hexane $(30 \mathrm{~mL})$ was slowly added $\mathrm{Et}_{3} \mathrm{Ga}(2.67 \mathrm{~g}$. $17.0 \mathrm{mmol}$ ) at room temperature. and followed by stirring for $3 \mathrm{~h}$. the volatiles were removed under vacuum. After the solids were dissolved in a mixture of toluene $(20 \mathrm{~mL})$ and THF $(20 \mathrm{~mL}), \mathrm{NaN}_{2}(4.97 \mathrm{~g} .76 .5 \mathrm{mmol})$ was slowly added The reaction mixture was refluxed for $12 \mathrm{~h}$, cooled to room temperature, and filtered. $\mathrm{NH}_{2} \mathrm{CH}_{3}$ (1 M solution in THF, 
$12.8 \mathrm{~mL} .25 .5 \mathrm{mmol}$ ) was added to the filtrate at room temperature. After stirring for $3 \mathrm{~h}$. removal of solvents gave a crude product. A pure product was obtained by sublimation at $50{ }^{\circ} \mathrm{C} / 0.01 \mathrm{~mm} \mathrm{Hg}$ (yield $4.60 \mathrm{~g} .89 .8 \%$ ). ${ }^{1} \mathrm{H}$ NMR (300.13 MHz, $\left.\mathrm{C}_{6} \mathrm{D}_{6}\right): \delta 0.505$ (q. $\left.\mathrm{Ga}\left(\mathrm{CH}_{2} \mathrm{CH}_{5}\right)=4 \mathrm{H}\right) .1 .239$ (t. $\mathrm{Ga}\left(\mathrm{CH}_{2} \mathrm{CH}_{3}\right)=6 \mathrm{H}$ ). 1.747 (s. $\mathrm{NH}_{2} \mathrm{CH}_{3} .3 \mathrm{H}$ ). 2.371 (s. br. $\left.\mathrm{NH}_{2} \mathrm{CH}_{3} .2 \mathrm{H}\right)$. FTIR: $2084 \mathrm{~cm}^{-1} \cdot v\left(\mathrm{~N}_{3}\right)$

Metal organic chemical vapor deposition. A horizontal. stainless steel high vacuum chamber was used to grow the $\mathrm{GaN}$ films. The $\mathrm{Si}$ substrates used for the growth were Si(111) wafers with the rectangular shape of $25 \times 8 \mathrm{~mm}$. The particular $\mathrm{Si}(111)$ surface was chosen to match its bulk symmetry with that of the hexagonal GaN. Before deposition. a silicon substrate was cleaned in deionized water and acetone. followed by piranha solution etching $\left(\mathrm{H}_{2} \mathrm{SO}_{4}: \mathrm{H}_{2} \mathrm{O}_{2}\right.$ $=3: 1$ ) for $30 \mathrm{~min}$ at $80^{\circ} \mathrm{C}$. The substrate was dipped into a $10 \% \mathrm{NH}_{4} \mathrm{~F}$ aqueous solution for $10 \mathrm{~min}$ to remove the native $\mathrm{SiO}_{2}$ formed on the surface. rinsed in deionized water. and dried with nitrogen gas. It was then immediately transferred into the growth chamber. The wet-cleaned silicon wafer was thermally degassed at $750{ }^{\circ} \mathrm{C}$ in a cold-wall reactor for 20 min. The base pressure of the CVD reactor was maintained at $\sim 1 \times 10^{-7}$ Torr. When vaporization of the precursor started. the pressure increased by an order of magnitude. The precursor temperature was kept at $70{ }^{\circ} \mathrm{C}$ and the substrate temperature was varied in the range $385-650{ }^{\circ} \mathrm{C}$. Each deposition experiment was carried out for $3 \mathrm{~h}$.

Characterization of the films. X-ray photoelectron spectroscopy (ESCALAB MK II. VG Scientific. Ltd.) was employed to analyze the chemical compositions of the $\mathrm{GaN}$ films obtained. The X-ray was non-monocluromated $\mathrm{Mg} \mathrm{K} \alpha$ radiation with the energy $1253.6 \mathrm{eV}$. The phase of the films was determined with a Rigaku D/MAX III-B powder X-ray diffractometer by using the $\mathrm{Cu} \mathrm{K} \alpha$ radiation. Surface morphology and thickness of the films were investigated by means of plan-view and cross-sectional scanning electron microscopy (JEOL JSM 840A) images. Photoluminescence was performed to evaluate the optical properties of the GaN films. A He-Cd laser ( $325 \mathrm{~mm}$ from Melles Griot) with a power density of 30 $\mathrm{mW} \mathrm{cm}{ }^{-2}$ was used to measure photoluminescence spectra at room temperature. The double monochromator had a focal length of $85 \mathrm{~cm}$. The detector was a CCD manufactured by Jobin Yron-Spex. cooled by liquid nitrogen during data acquisition. The resolution of the spectrum acquisition was $0.27 \mathrm{~nm}$ with an integration time of $5 \mathrm{~s}$.

\section{Results and Discussion}

Figure 1 shows an XP survey spectrum obtained from a $\mathrm{GaN}$ film grown on $\mathrm{Si}(111)$ at $400^{\circ} \mathrm{C}$. The survey spectrum clearly exhibits the photoelectron peaks corresponding to the $\mathrm{Ga} 3 \mathrm{~d} . \mathrm{Ga} 2 \mathrm{p} . \mathrm{N}$ 1s. and various Auger peaks of gallium and nitrogen. revealing the formation of a $\mathrm{GaN}$ film. Besides these relevant peaks. there also appear $\mathrm{O} 1 \mathrm{~s}$ photoelectron peak and O KVV and C KVV Auger peaks that are attributed to surface contamination of the newly formed film by air and/or moisture during sample transfer to the analysis

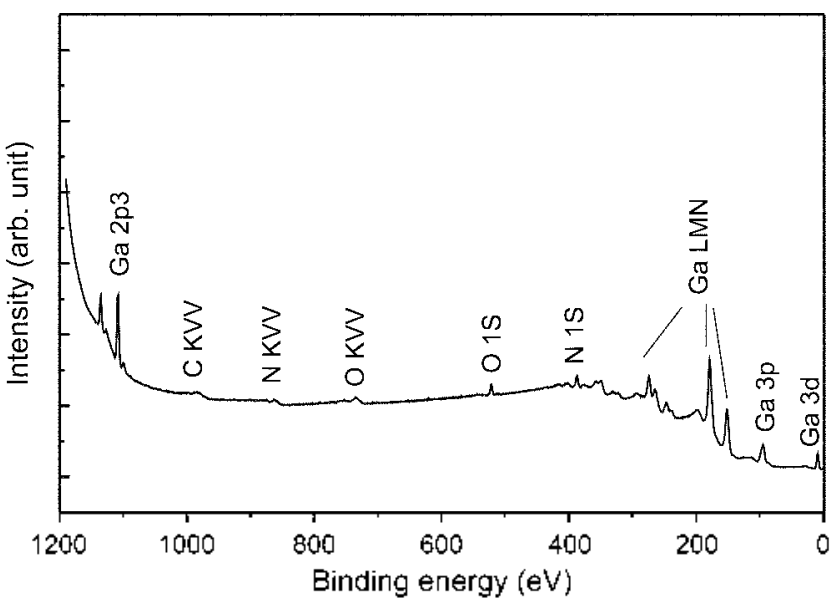

Figure 1. X-ray photoelectron survey spectrum of a GaN film deposited at $400^{\circ} \mathrm{C}$.

chamber of the XPS machine. In this spectrum. the $C$ ls peak is not clearly observed because it is buried in the Ga LMM Auger peaks. The atomic ratio of $\mathrm{Ga}$ to $\mathrm{N}$ calculated using the peak area ratio of the $\mathrm{Ga} 3 \mathrm{~d}$ peak to $\mathrm{N}$ ls peak is $1.00: 0.94$. The $\mathrm{GaN}$ film was found to include $8 \%$ of oxygen in its surface region. For the elimination of the surface contanination by carbon. the surface of the deposited film was sputter etched by an $\mathrm{Ar}^{+}$beam. After etching for a short while, the $C$ 1s peak practically disappeared. This indicates that carbon exists mostly in the surface region of the film. The XPS analysis evidently shows that the GaN film obtained is stoichiometric and contains low levels of impurities. The carbon content in the film obtained by the analy sis of the XP spectrum after $\mathrm{Ar}^{+}$etching. however. was not quite negligible. being somewhat lower than $3 \%$.

$\mathrm{X}$-ray diffraction technique was employed to investigate the phase and orientation of the $\mathrm{GaN}$ films. For the films grown at low temperatures $\left(<400^{\circ} \mathrm{C}\right)$. XRD patterns showed $h$-GaN $(0002), h$-GaN $(10 \overline{1} 1)$, and $h$-GaN(1013) peaks. Figure 2 shows $\theta-2 \theta$ XRD patterns for the GaN films deposited on $\mathrm{Si}(111)$ in the temperature range $400-650^{\circ} \mathrm{C}$. As shown in the figure, intense reflection peaks of $\mathrm{Si}(111)$. GaN $(0002)$. and the weak GaN $(0004)$ peak are observed at $2 \theta=28.8^{\circ}$. $34.6^{\circ}$, and $73.0^{\circ}$. respectively. This indicates that the $\mathrm{GaN}$ films deposited on $\mathrm{Si}(111)$ were $h$-GaN and grown with a highly preferred orientation in the [0001] direction at temperatures above $\sim 400^{\circ} \mathrm{C}$. From the intensity variation of the $\mathrm{GaN}(0002)$ peak. the optimum temperature for the growth of GaN using the precursor azidodiethylgallium methylamine adduct is $\sim 500{ }^{\circ} \mathrm{C}$. The intensity of the $\mathrm{GaN}(0002)$ peak shows a sharp decline at $550^{\circ} \mathrm{C}$ and a gradual increase up to $650{ }^{\circ} \mathrm{C}$. This phenomenon has been found reproducible and is probably due to increased growth rate without enough time for crystallization of the films at this temperature range as will be explained later by the growth rate vs. temperature plot or the Arrhenius plot of the growth rate in Figure 4.

The surface morphology of the GaN films was characterized by plan-view SEM images. Figure 3 shows the SEM images of the GaN films deposited on $\mathrm{Si}(111)$ at four different 


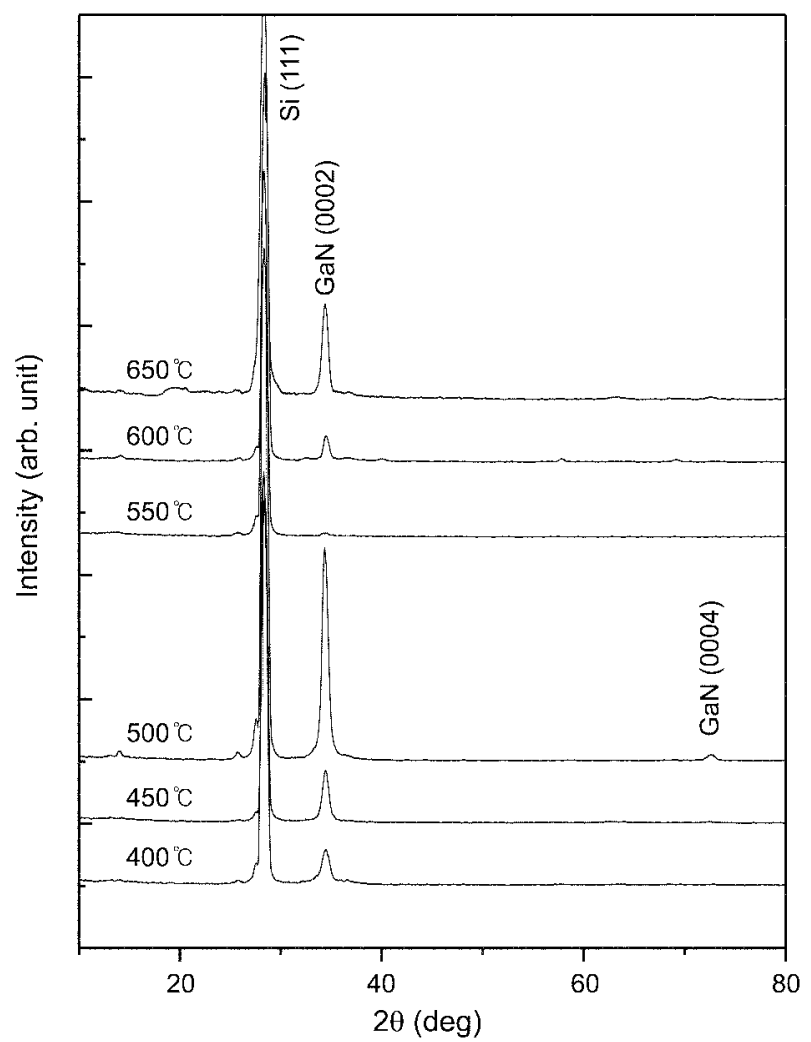

Figure 2. XRD ( $\theta-2 \theta$ scans) pattens of the GaN films deposited at various substrate temperatures.

growth temperatures. It can be seen that the GaN films were grown with different morphology depending upon the growth temperature. Although Figure 3(a) shows a seemingly very smooth surface for the film grown at $385^{\circ} \mathrm{C}$. its crystallinity was not well developed judging from the corresponding XRD pattern (not shown). Figure 3(b) shows formation of a granular film at $400{ }^{\circ} \mathrm{C}$. The surface is not smooth and has void-containing structures. At $500^{\circ} \mathrm{C}$. the grains were somewhat merged into a denser film. with concurrent development of crỵstallinity (Figure 2). At $600{ }^{\circ} \mathrm{C}$. larger grains appeared

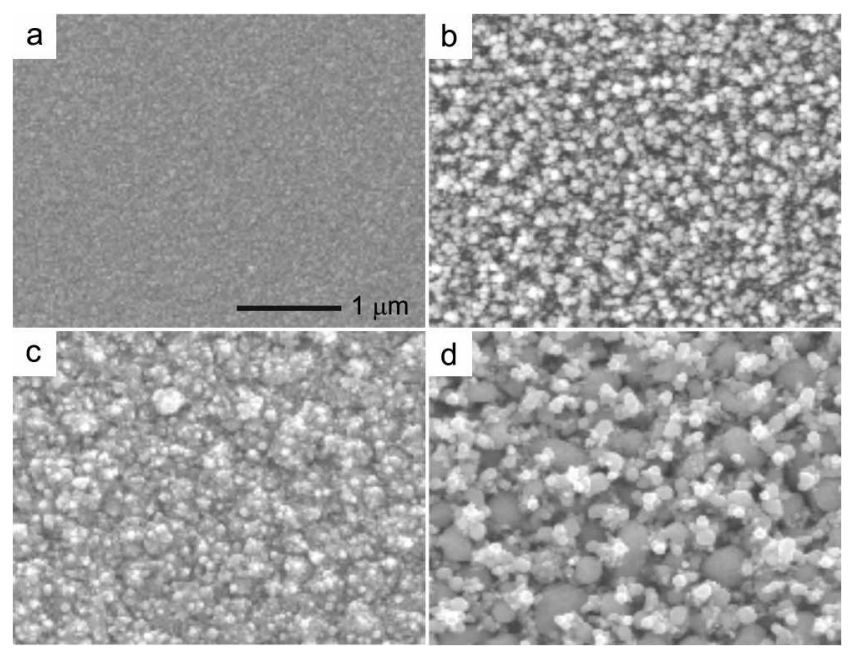

Figure 3. SEM images of the GaN films grown at (a) $385^{\circ} \mathrm{C}$, (b) $400^{\circ} \mathrm{C}$, (c) $500^{\circ} \mathrm{C}$, and (d) $600^{\circ} \mathrm{C}$
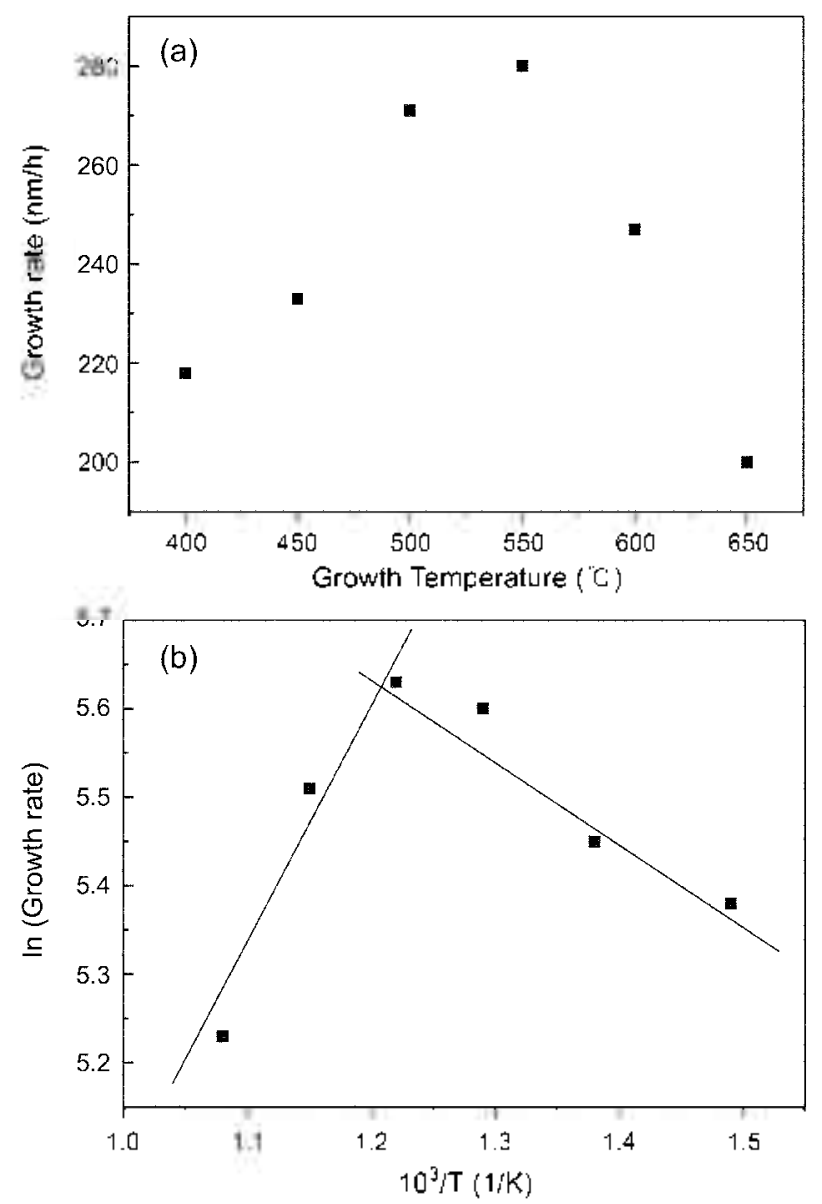

Figure 4. Growth rates at various temperatures (a) and the Arrhenius plot (b).

and the crystallinity deteriorated judging from the XRD pattern. However. at the growth temperature of $650^{\circ} \mathrm{C}$. as shown in Figure 2, the crystallinity inproved again.

The growth rates of the $\mathrm{GaN}$ films at various temperatures were found from thickness measurements by cross-sectional SEM images and plotted in Figure 4(a). The maximum growth rate is aclieved at $\sim 550^{\circ} \mathrm{C}$. which is $\sim 280 \mathrm{~mm} / \mathrm{h}$. This coincides with the poorest crystallinity for which the XRD intensity of the GaN $(0002)$ peak is the minimum as manifested by Figure 2. In Figure 4(b). an Arrhenius plot. In (growth rate) $v .1 / T$. is shown in which there appear two different growth regions. At lower temperatures. the points on the negative slope denote the deposition govemed by the surface reaction kinetics. whereas. at higher temperatures. the points on the positive slope denote the deposition governed by the diffusion of the reactant to the surface. Combined with Figures 2 and 3. Figure 4 indicates that at the highest growth rate (at $\sim 550{ }^{\circ} \mathrm{C}$ ), the film formed simply does not have ample time for crystallization. At even higher temperatures. the growth rate decreases again (not shown) because of decreased sticking probability of the reactant precursor.

The optical property of the GaN films was characterized by photoluminescence measurements. PL measurements were performed at room temperature. Figure 5 shows a band 


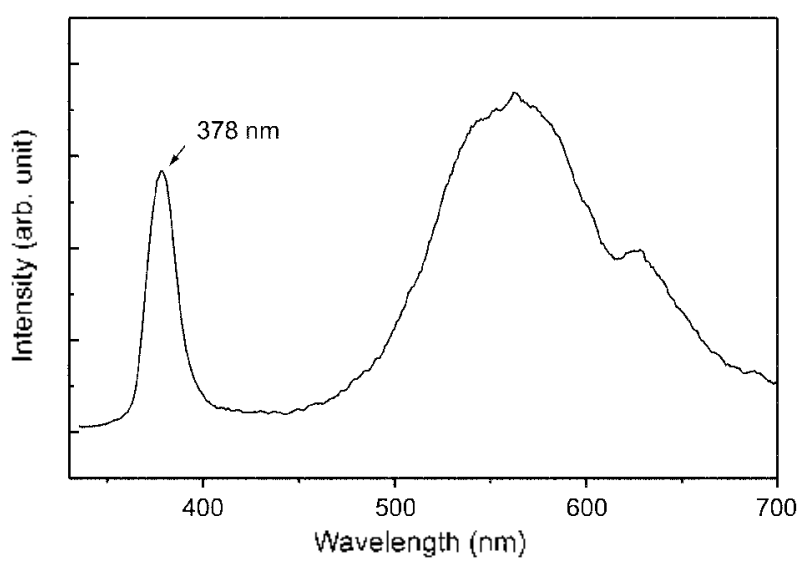

Figure 5. Room temperature PL spectrun of a GaN filn grown at $400^{\circ} \mathrm{C}$.

edge emission peak at $378 \mathrm{~nm}$ and a broad yellow luminescence peak centered at $\sim 560 \mathrm{~mm}$ for a GaN film grown at 400 ${ }^{\circ} \mathrm{C}$. The sharp peak at $378 \mathrm{~nm}$ is characteristic of a hexagonal $\mathrm{GaN}$ film. The large and broad yellow peak may be attributed to the deep levels caused by carbon contamination or lattice defects.= This is in contrast with our result of growing $h$ GaN films by using azidodiethy'gallium methy'lhydrazine adduct ${ }^{\text {" }}$ "which showed no appearance of a yellow band and suggests that the growth of $h$-GaN films by using the precursor azidodiethylgallium methylamine adduct has not been fully optimized.

\section{Conclusion}

The single precursor azidodiethylgallium methylamine adduct has been synthesized and employed in the MOCVD of hexagonal gallium nitride. It was found that the precursor has the effect of drastically lowering the deposition temperature of the $h-\mathrm{GaN}$ films compared to conventional MOCVD processes in which separate sources for gallium and nitrogen are used. XPS. XRD. SEM. and PL measurements indicate that the MOCVD of $h$-GaN by using the precursor azidodiethy'lgallium methylamine adduct yielded films that are generally comparable in characteristics to previously reported films by using different single precursors. The precursor may also be promising as a non-pyrophoric source material for $\mathrm{GaN}$ deposition. However. optimization of the
MOCVD process seems still necessary judging from the XRD. SEM. and PL data.

Acknowledgment. This research has been supported by the Ministry of Science and Technology through the National Research Laboratory (NRL) Program.

\section{References}

1. Nakamura S.; Fasol, G. The Blue Laser Diode; Springer-Verlag: Berlin. Heidelberg, Germany, 1997; pp 24-25.

2. Davis. R. F.: Sitar. Z.: Williams. B. E.: Kong. H. S.: Kim. H. T.: Palmour. J. W.: Edmond. T. A.: Ryut. J.: Glass. J. T.: Carter. C. H.. Jr. Mater Sci. Engr. B 1988. 1.77-104.

3. Karpinsky. J.: Jun, J.; Porowsky. A. J. Cnst. Growth 1984. 66. 110

4. Strite, S.: Morkoç, H. J. Iac. Sci. Techol. B 1992. 10. 1237-1266.

5. Chu. T. L. J. Electrochem. Soc. 1971. 118. 1200)-1203.

6. Zhang. H.: Ye. Z.: Zhao. B. phus. stat. sol. fal 2000. 177. $485-493$.

7. Barfels. T.: Fitting. H.-T.: Tansons. J.: Tale. I.: Veispals. A.: von Czarnowski. A.; Wulff. H. Appl. Surf. Sci. 2001. 179, 191-195.

8. Kim. M.-H.: Bang, Y.-C ; Park, N.-M; Choi. C.-J.: Seong. T.-Y.: Park, S.-J. Appl. Phus. Lett. 2001. 78. 2858-2860.

9. Andrews. J. E.: Littlejohn. M. A. J. Electrochem. Soc. 1975. 122. $1273-1275$.

10. Kouvetakis. I.: Beach. D. B. Chem. Mater 1989. 1.476-478.

11. Atwood, D. A.: Jones. R. A.; Cowley, A. H: Atwood, J. L:; Bott, S. G. J. Orgumontet Chem. 1990, 394. C6-C8.

12. Neumaver. D. A.; Cowley, A. H.: Decken, A.; Jones, R. A.: Lakhotia. V.: Ekerdt. J. G. J. Am. Chem. Soc. 1995. 117. 58935894.

13. Lahhotia. V: Neumayer. D. A.: Cowley. A. H.: Tones. R. A.: Ekerdt, J. G. Chem. Hater: 1995. 7, 546-552.

14. MoMurran. J.: Kouvetakis, J.; Nesting, D. C.: Simith, D. J.: Hubbard. J. L. J. Am. Chem. Soc. 1998, 120. 5233-5237.

15. McMurrant. J.: Kouvetakis. T.: Smith. D. T. Appl. Plys. Lett 1999. 74. $883-885$

16. Park. H. S.: Waezsada. S. D.: Cowley. A. H.: Roesky. H. W. Chen Mater 1998, 10. 2251-2257.

17. Boo. J.-H.; Lee, S.-B.: Kim, Y.-S.; Park. J. T:; Yu, K.-S.: Kim, Y. phus. stat. sol. fal 1999.176,711-717.

18. Devi. A.: Rogge. W: Wohlfart. A.: Hipler. F.: Becker. H. W: Fischer. R. A. Chem. Iap. Deposition 2000. 6. 245-252.

19. Lee. I. H.: Yoo. S. H.: Lee. Y. K.: Kim. C. G.: Yang. Y. S.: Kim. Y.: Jeon. H. J. Korem Phws. Soc. 2001, 39, S242-S245.

20. Sung. M. M. Kim. C.: Yoo, S. H.; Kim. C. G.; Kim. Y. Chent. Iip. Deposition 2002, 8. 50-52.

21. Cowley. A. H.: Tones. R. A. Angew: Chem Iht Ed Engl 1989. 28. $1208-1215$.

22. Detchprohm. T.: Amano. H.: Hiramatsu. K.: Akasaki. I. J. Chst Growth 1993. 128. 384-390. 